[Acta Geophysica, Vol 65, Issue 4, pp645-657]

\title{
A GIS approach to seismic risk assessment with an application to mining related seismicity in Johannesburg, South Africa
}

\author{
Keagen LIEBENBERG ${ }^{1}$, Ansie SMIT ${ }^{2}$, Serena COETZEE ${ }^{3}$, Andrzej KIJKO ${ }^{4}$
}

(1) Centre for Geoinformation Science, Department of Geography, Geoinformatics and Meteorology, University of Pretoria, Pretoria, South Africa; e-mail: keagenliebenberg@gmail.com

(2) University of Pretoria Natural Hazard Centre, Africa, Pretoria, South Africa; e-mail: ansie.smit@up.ac.za

(3) Centre for Geoinformation Science, Department of Geography, Geoinformatics and Meteorology, University of Pretoria, Pretoria, South Africa; e-mail: serena.coetzee@up.ac.za (4) University of Pretoria Natural Hazard Centre, Africa, Pretoria, South Africa; e-mail: andrzej.kijko@up.ac.za

Corresponding author: Ansie Smit, University of Pretoria Natural Hazard Centre, Africa, Pretoria, South Africa; e-mail: ansie.smit@up.ac.za ; Tel: +27 12 4202282; ORCID: 0000-0003-0315-0875

\begin{abstract}
The majority of seismic activity in South Africa is related to extensive mining operations, usually in close proximity to densely populated areas where a relatively weak seismic event could cause damage. Despite a significant decrease in mining operations in the Witwatersrand area, the number of seismic events appears to be increasing and is attributed to the acid mine drainage problem. The increased seismicity is raising concern amongst disaster management centres and in the insurance industry. A better understanding is required of the vulnerability and the size of the potential loss of people and infrastructure in densely populated Johannesburg and its surrounding areas. Results of a deterministic seismic risk, vulnerability and loss assessment are presented by making use of a geographic information system (GIS). The results illustrate the benefits of using GIS and contribute to a better understanding of the risk, which can assist in improving disaster preparedness.
\end{abstract}

Key words: acid mine drainage, Johannesburg, seismic risk, vulnerability, GIS

\section{INTRODUCTION}

From a tectonic point of view, South Africa is a typical stable continental area, also known as an intraplate region. These regions are usually characterized by low-level seismic activity compared to world standards, with seismic events randomly distributed in both space and time. Most natural (tectonic origin) seismic activity takes place in the Western Cape and northern parts of KwaZulu-Natal (Fig. 1). However, the main contributor to seismic activity in South Africa is mine-related which occurs in the North West, Gauteng and Free State provinces. These types of events are due to deep-level gold and platinum mining. Extensive investigations into the seismic hazard and risk for South Africa based on both natural and mining-related events, have been done over the years (Kijko et al., 2002; Van Aswegen, 2005; Esterhuyse et al., 2014; Kijko et al., 2016). These investigations also looked at what is expected to happen to mine related seismic activity once mining ceased. However, very little research has gone into the effect on mine related seismicity after mine closures when increased water levels in the mine voids are observed.

After the closure of a mine, all operations are terminated. The mine water is therefore no longer extracted, resulting in the flooding of underground mine voids and an increase in the underground pressure. The increased water levels also act as a chemical and geochemical catalyst between the mine rock strata, mine wastes, and oxygen, causing the water in underground voids in the mines to become acidic (Birch, 2013; du Plessis et al., 2015). Water under high constant pressure is known to lubricate fractures, fissures and faults, 
which weakens the clamping forces. The stability of the fractures, fissures and faults are affected allowing for seismic events to be generated (Carder, 1945; Durrheim, 2006; Goldbach, 2010).

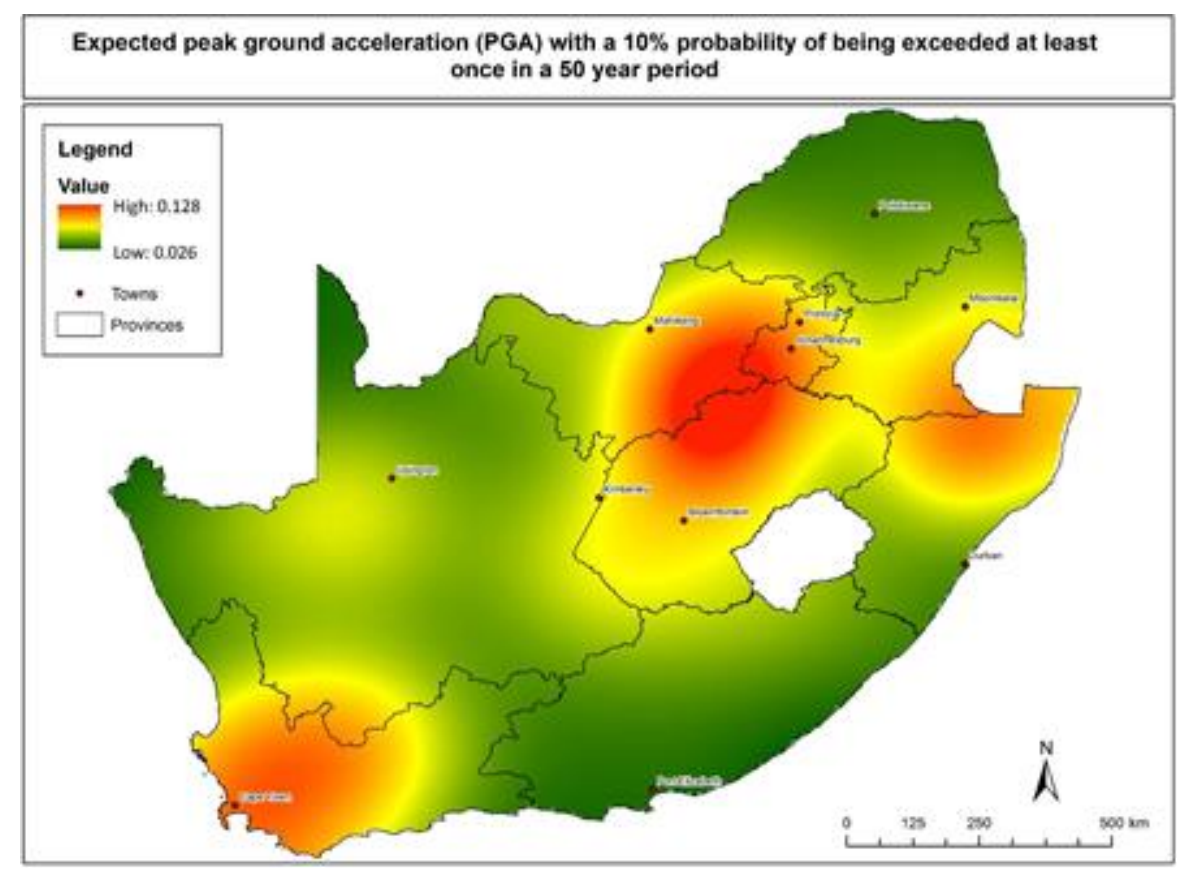

Fig. 1. Map of the expected peak ground acceleration (g) with a $10 \%$ probability of being exceeded in a 50year period for South Africa (Kijko et al., 2016).

The flooding of mine voids and the resulting seismic activity is not a new phenomenon but the close proximity of the metropolitan city of Johannesburg is of concern. During active mining operation in the Witwatersrand area in South Africa, a maximum event of $M_{L} 5.3$ was observed (Coetzee et al., 2010). If the magnitude of seismic activity reaches the same level as observed during the height of mining operations, as suggested by local and international studies, a magnitude of similar size can be expected to occur. In the past, events of this magnitude have caused structural damage and business disruption in the Witwatersrand (Coetzee et al., 2010).

During the past few years, the frequency of seismic events appears to be on the increase, even though the number of active mines in the area has drastically decreased - potentially due to the presence of acid mine water. A 2010 report by the Department of Water Affairs on mine water management in the Witwatersrand goldfields reported an increase in the average number of monthly observed seismic events from 5.9 events before pumping in the mine voids stopped to 11.7 events (Coetzee et al. 2010). A significant increase is also observed in Fig. 2, in the cumulative released energy by seismic events between 2000 and 2010 (Kijko et al., 2012). Since it is expected that the maximum possible induced or triggered event magnitude due to acid mine water can fall in the same range as observed during active mining (Coetzee et al., 2010), the increased seismic activity raised concerns with relevant parties such as the general population living and working in the area, disaster management agencies as well as the insurance and reinsurance industry. These concerns include what the likelihood is that more seismic events with larger and potential damaging magnitudes can occur and what the foreseeable loss of life and infrastructure would be. 


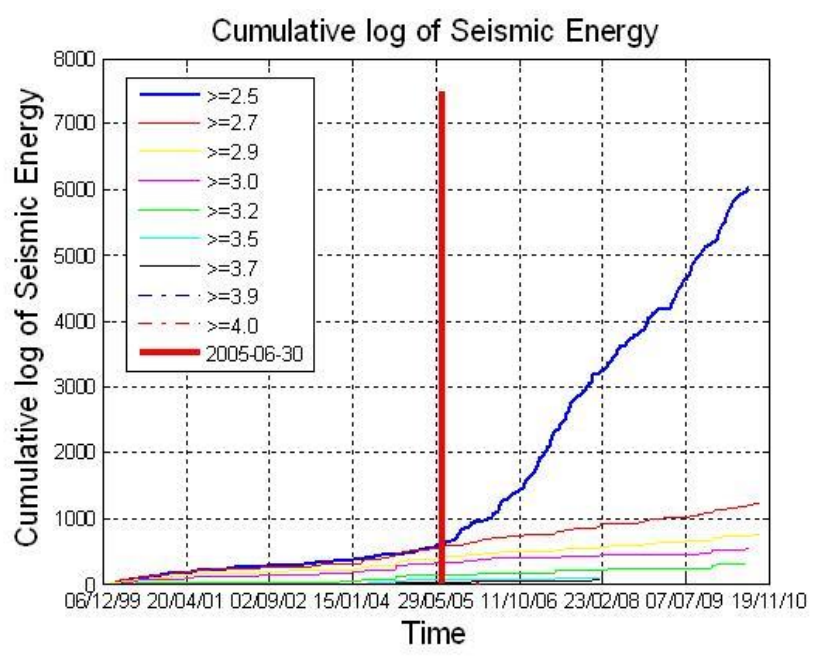

Fig 2. Cumulative log of the seismic energy released by seismic events in Johannes-burg area with $M_{L}$ magnitudes 2.5 and stronger during the period 2000/01/01 - 2010/12/31 (Source: Kijko et al. 2012)

The authors endeavoured to address these concerns firstly by investigating potential factors that could have a positive or negative impact on acid mine water induced seismic activity (du Plessis et al., 2015), and second, to investigate different seismic risk scenarios in the Witwatersrand area based on the current observed seismic activity in the area. Both papers focus on applying GIS-tools in the assessment procedures.

Risk is generally defined as the probability of losing something of value. A risk assessment can quantitatively or qualitatively estimate the risk that is associated with a specific hazard (or threat). The risk assessment process involves the evaluation of the observed hazard and vulnerability (susceptibility to loss), as well as the size of the potential loss (van Westen, 2013). A comprehensive risk assessment combines the prospective risk to infrastructure with the prospective risk of event-related deaths. Seismic risk assessments should therefore assess the potential loss associated with the probability of an earthquake occurring in or within close proximity to the defined geographic area. The correlation of the observed damage to buildings and/or casualties (loss) with the observed intensity of the seismic hazard should also be taken into consideration.

Probabilistic and deterministic procedures can be applied to seismic hazard and seismic risk analyses (Davies and Kijko, 2003; Kijko, 2011, Kijko et al, 2015). Probabilistic approaches assess the seismic hazard and risk levels in an area by taking into consideration all the potential earthquake scenarios and their probability of occurring within a specified time period (Yuan, 2003), while deterministic methods focus on specific earthquake scenarios of interest. While the probabilistic methods provide a more holistic picture, the deterministic method is easier to use when accounting for incomplete and uncertainty information (Mualchin, 2011). The authors therefore chose to apply the deterministic approach the seismic risk assessment in the City of Johannesburg (CoJ).

Comprehensive reviews of seismic risk and loss estimation methodologies have been published since the early 1980s among others Reitherman (1985), Whitman (1986), Keilis-Borok et al. (1984), ATC-13 (1985), FEMA 249 (1994), Grünthal (1998), Frolova et al. (2006), ASCE 41-06 (2007). The insurance industry also played a crucial role furthering the methodology in earthquake loss estimation (Steinbrugge, 1982; Algermissen et al., 1972). These studies focus primarily on the development of damage curves which connect a ground motion parameter such as peak ground acceleration or Modified Mercalli intensities to damages and losses since serious casualties mostly correlates with extreme damage experienced by a minority of buildings. The deterministic seismic risk is subsequently determined by assessing the deterministic seismic hazard, assigning the respectable damage curves and obtaining the relevant vulnerability curve by plotting the mean damage factor against the hazard and connecting it to a loss value. 
The popularity of GIS in seismic risk assessment has increased over the years. Although the background calculations do not differ from the traditional approaches as discussed above, it does provide some added advantages. The system is capable of facilitating the amalgamation, organization, geo-referencing and displaying of large sets of heterogeneous information - often of varying formats and scale. It also serves as a tool with which the different stages of risk assessment can be monitored and used to test hypothetical scenarios. GIS-based risk assessments provide an intuitive, easy-to-interpret tool to make a complex phenomenon understandable for non-specialised users in local and national government structures, disaster management centres and economic departments (Servi, 2004; Rivas-Medina et al., 2013).

In this paper, we describe a GIS approach to the standard deterministic seismic risk assessment by focussing on the potential losses to population and infrastructure. The GIS-based approach is described in Section 2. In Section 3, the results of a risk assessment for two different earthquake scenarios in two suburbs in CoJ Metropolitan Municipality are presented and discussed. Section 4 presents a conclusion.

\section{GIS-BASED SEISMIC RISK ASSESSMENT}

\subsection{Overview}

A summary of the applied GIS-based approach used to assess the seismic risk in CoJ based on the hazard, vulnerability, and potential loss analysis is provided in du Plessis et al. (2015) and described here in more detail. Two potential scenario earthquakes and their impact on the people and buildings are investigated in the CoJ based on hypothetical events in the Germiston area, which is currently experiencing high levels of seismic activity (Fig. 3).

Figures 4 and 5 describe the process followed during the assessment of the seismic risk associated with buildings and people. The methodology applied by the authors for assessing the vulnerability of people and buildings is defined by Servi (2004) and Ciriannia et al. (2008), and is described later in this section.

First, two areas in CoJ were identified: Sandton Central Business District (CBD) (which includes the StatsSA subplaces of Sandhurst, Sandown and Morningside) and Johannesburg CBD (which includes the StatsSA sub-places of Johannesburg SP; Marshalls Town; City and Suburban; and New Town) (Statistics South Africa, 2013). The two areas (Fig. 6) were chosen since they consist mainly of high-rise buildings filled with hundreds of people during the day. They are also situated in the economic hub of South Africa.

\subsection{Seismic Hazard Assessment}

Next, seismic hazard is determined by modelling the effect of two scenario earthquakes with different magnitudes. Based on investigations of areas exhibiting similar geological and tectonic characteristics, Fenton et al. (2006) believe the expected maximum possible earthquake magnitude $m_{\max }$ of a tectonic seismic event in Gauteng to be in the order of 7.0. However, current seismic hazard models in South Africa assumes that an $m_{\max }$ of magnitude 6.8 can be expected for tectonic earthquakes and that a mine related event in the Gauteng region will not exceed 5.5-5.6 (Davies and Kijko, 2003). The assessment by Davies and Kijko (2003) however does not take into consideration the potential effects of acid mine water on significant component stresses currently present in Gauteng. 


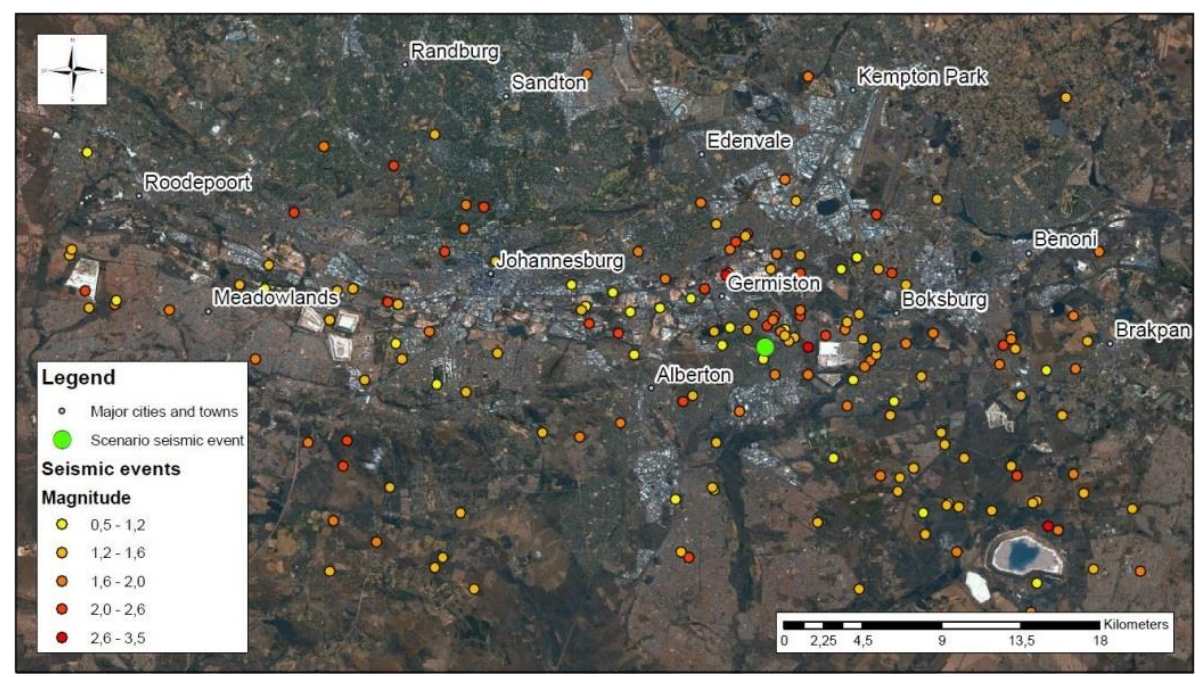

Fig 3. Observed seismic activity in Johannesburg region between 2011 and 2014 for all magnitude levels (du Plessis et al., 2015).

The proposed GIS approach to modelling the impact of a hypothetical seismic event is done by focusing on events of magnitudes $M_{L} 5.3$ and $M_{L} 6.0$ in the two identified areas. The epicentre (location) of both the scenario events is presented as a green point in Fig. 3. The procedure to calculate the seismic risk is illustrated in Figures 4 and 5 . The numeric values in the figures represent weights, explained further down.

In seismic hazard analysis, the Modified Mercalli (MM) intensity scale is one of the tools used to describe the relationship between the ground motion produced by a seismic event and the resulting damage (Wood and Neumann, 1931; Sieberg, 1923). This scale is divided into 12 levels, each describing reactions of people and animals as well as the observed effects in and on infrastructures. Level I of the scale describes those events ranging between nothing was felt to slight disturbances felt by people and observed in the surrounding environment. Level XII refers to the complete destruction of small and major infrastructures as well as physically visible deformations in the geology.

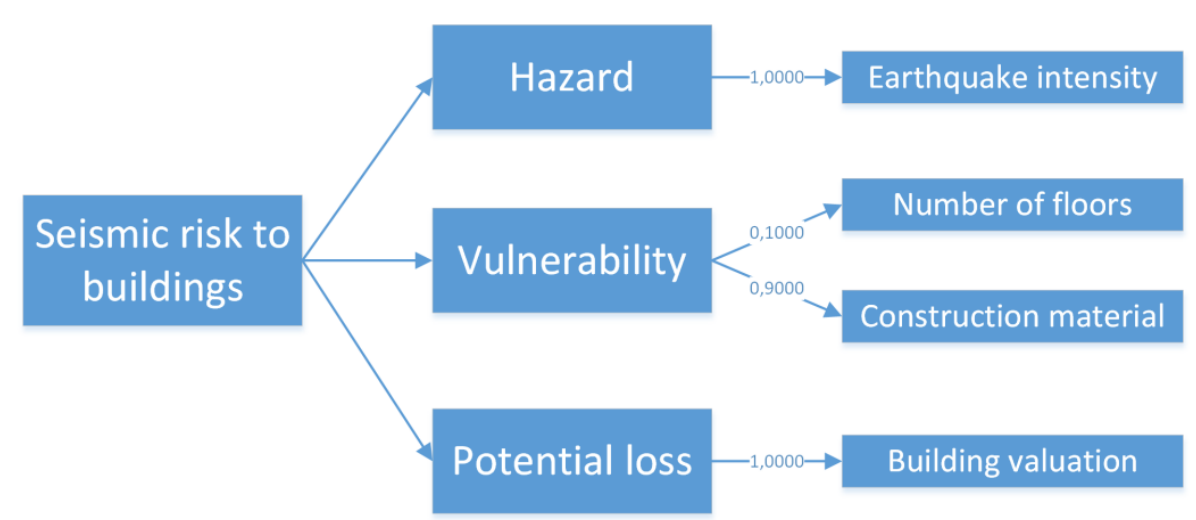

Fig 4. A summary of the procedure to calculate the seismic risk to buildings (du Plessis et al., 2015). 


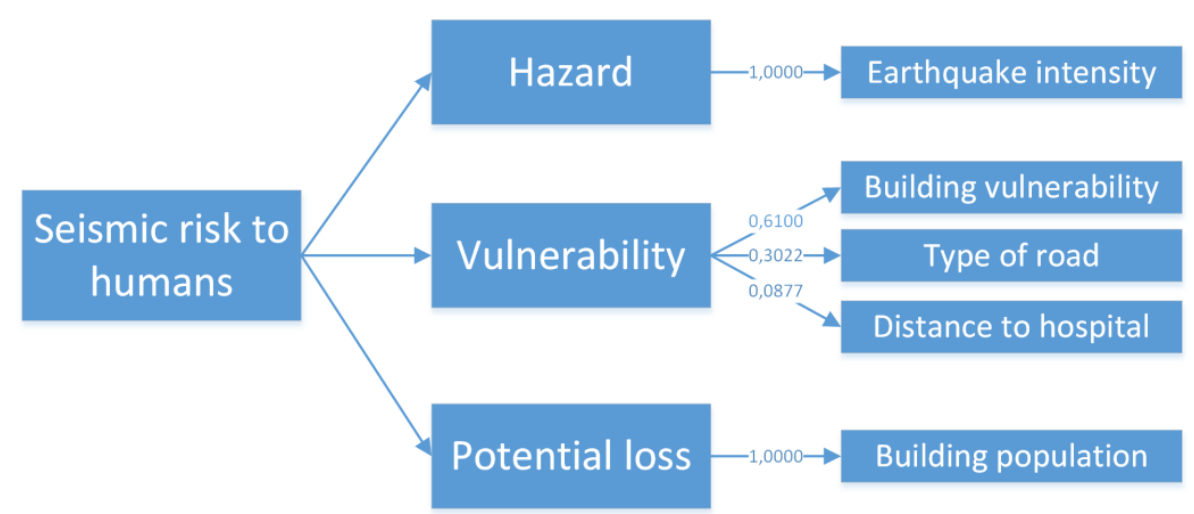

Fig 5. A summary of the procedure to calculate the seismic risk to people (du Plessis et al., 2015).

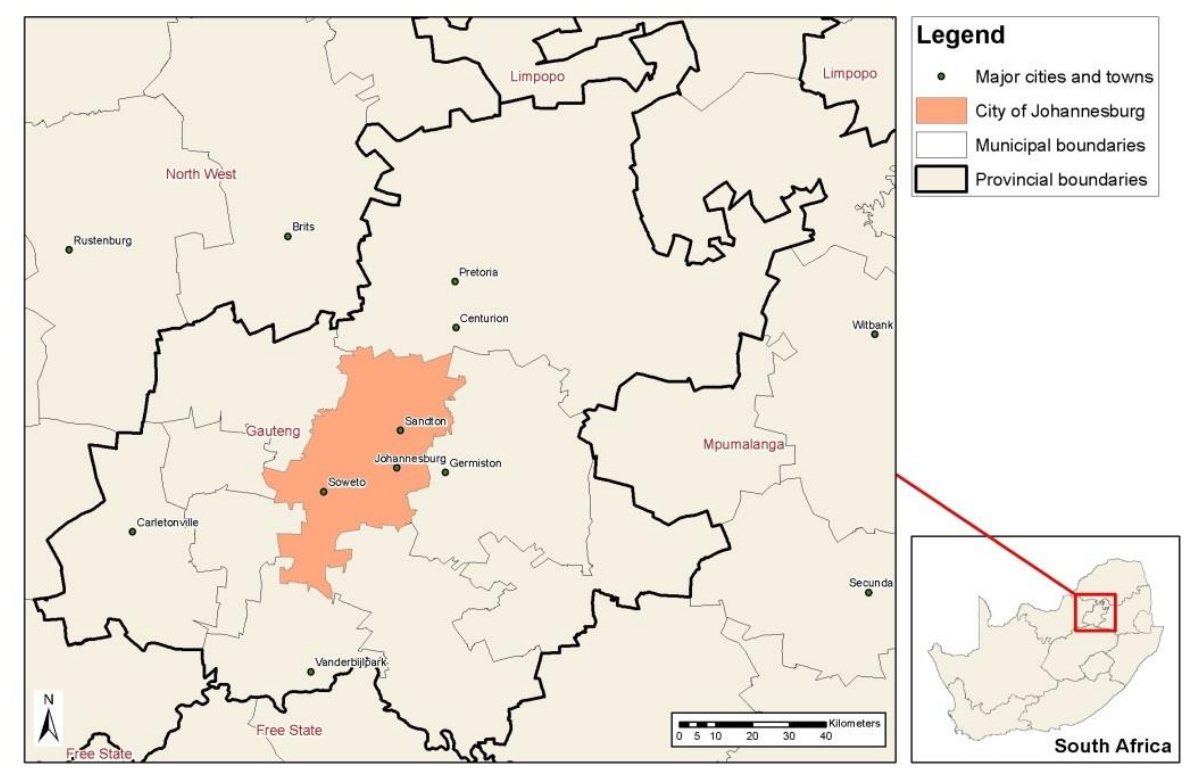

Fig 6. Map showing the positions of the Johannesburg and Sandton CBD's within the City of Johannesburg.

The epicentral intensity $I_{0}$ is defined as the MM intensity at the earthquake epicentre and is a function of earthquake magnitude $m$ (Richter, 1958)

$$
I_{0}=b_{1} m+b_{2}
$$

with $b_{1}=1.5$ and $b_{2}=-1.0$ defined as constants. The MM intensity $I$ (@site) at epicentral distance $r$ (in km) is provided by the so-called intensity prediction equation (IPE) of a typical functional form (Lay and Wallace, 1995)

$$
I(@ \text { site })=I_{0}+a_{1}+a_{2} \log r+a_{3} r .
$$


with $a_{1}=0.41544, a_{2}=-0.34261$ and $a_{3}=-0.025702$. The numerical values of coefficients $a_{1}, a_{2}, a_{3}$ are different for different regions and are usually estimated from MM intensity distribution maps.

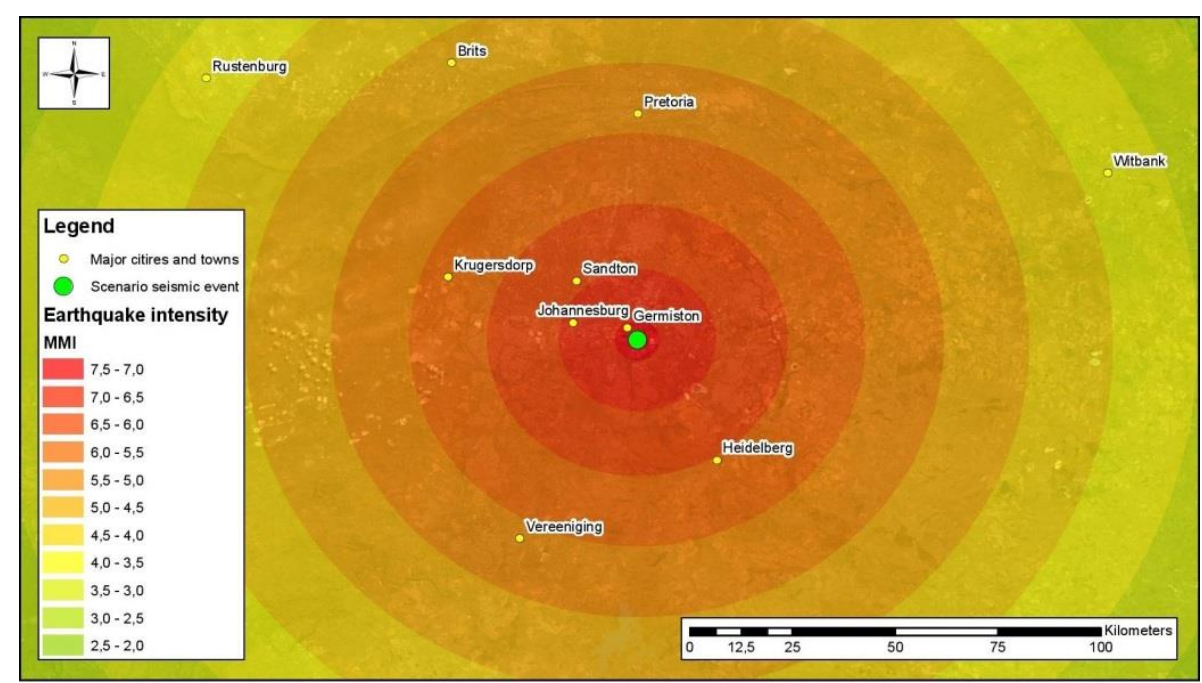

Fig 7. Intensity map showing the attenuation from the epicenter of the MM intensity IV scenario earthquake of magnitude $M_{L}$ 5.3.

Figures 7 and 8 respectively depict the predicted MM intensity as a function of epicentral distance for the scenario earthquakes of magnitude $M_{L} 5.3$ and 6.0 in the investigated area. The estimated MM intensities for the $M_{L} 5.3$ earthquake range from IV to VI. The resulting distribution of intensities (Fig. 7) suggests that an event of magnitude 5.3 would mostly affect the areas within close proximity to its epicentre causing minor damage, but may not have a significant impact within CoJ itself (du Plessis et al., 2015). Significantly larger intensities are predicted for the magnitude $M_{L} 6.0$ earthquake. All the estimated intensities exceed $V$ with some areas exhibiting intensities of VII and $1 / 2$ and larger. Such intensities are classified as strong enough to cause the destruction of poorly built structures. A magnitude 6.0 seismic event at some distance from the epicentre, can therefore generate intensities to cause significant damage in CoJ.

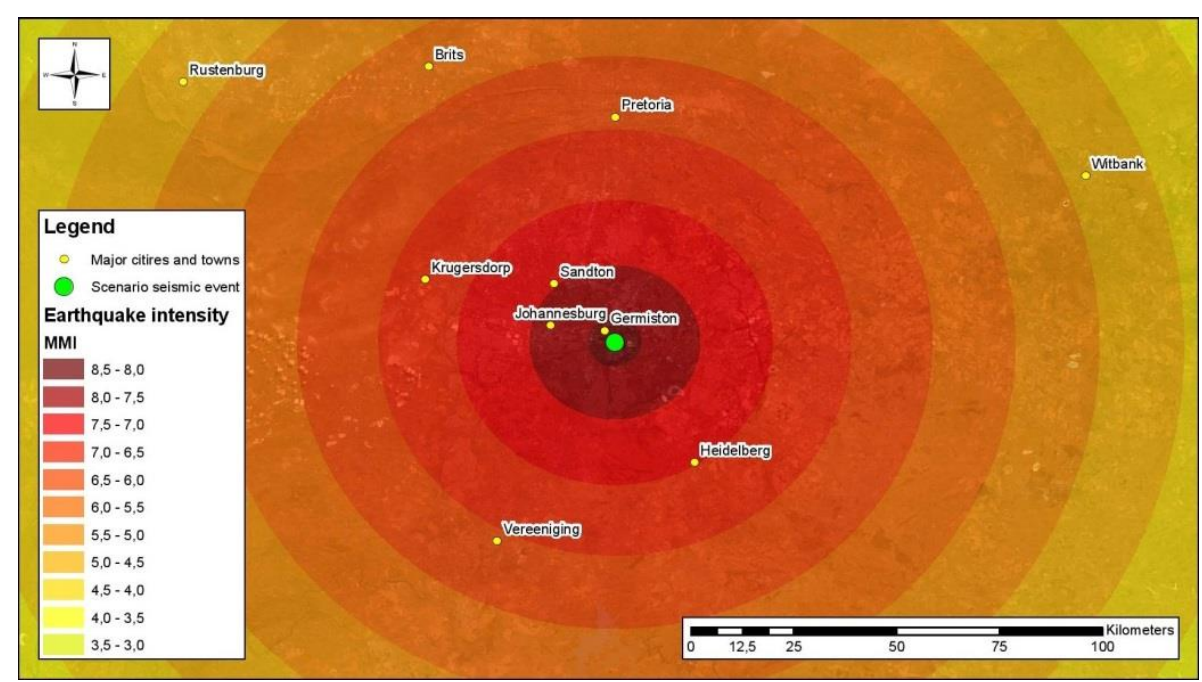

Fig 8. Intensity map showing the attenuation from the epicenter of the MM intensity VI scenario earthquake of magnitude $M_{L} 6.0$ (du Plessis et al., 2015). 


\subsection{Seismic Vulnerability Assessment}

In this study, the vulnerability assessment of people and buildings is based on a framework as discussed in Servi (2004) and put forward by Ciriannia et al. (2008). The four identified steps are:

1. Identify evaluation variables: examining the extent of the vulnerability analysis to be performed. This can include social risk (e.g. population distribution and building damage) and systematic vulnerability (e.g. distance from medical care and accessibility).

2. Estimate potential infrastructure damage: variables needed to assess potential damage includes building age and condition, the surrounding ground soil structure of building, and dimensions.

3. Standardization of measurement scales of the variables in step 2. Ciriannia et al. (2008) suggests a scale of $[0,1]$ be used.

4. Determining the weights on a scale of importance for the standardized criteria in step 3. Ciriannia et al. (2008) proposes that a pairwise comparison (a method of comparing different entities to decide on a preferred one) be used to rank the importance of criteria. An example of an importance scale is shown in Table 1. A comparison of each criterion on a scale of importance will result in a set of criteria weights.

Building vulnerability assessment in Johannesburg CBD and Sandton CBD required identification of the building types. However, due to constraints in the availability of building information in CoJ, a few specific individual buildings were identified for analysis. Additional information of the identified buildings' attributes was obtained from a website with a building catalogue (SkyScraperPage.com, 2014a, 2014b).

Variables such as building age, construction material, building condition and a number of storeys of the building are used by Servi (2004). In this study, only the number of floors and the construction material were considered as information about the condition of buildings was not available. The variable, building age, was not considered in this study since the general age of buildings in CoJ are much younger than those in Servi's study area, Turkey, which can be up to 400 years old.

Table 1: The scale of relative importance to be used in a pairwise comparison (Source: Malczewski, 1999).

\begin{tabular}{|c|l|}
\hline $\begin{array}{c}\text { Intensity of } \\
\text { Importance }\end{array}$ & \multicolumn{1}{c|}{ Definition } \\
\hline 1 & A and B of equal importance \\
\hline 2 & A equally to moderately more important than B \\
\hline 3 & A moderately more important than B \\
\hline 4 & A moderately to strongly more important than B \\
\hline 5 & A strongly more important than B \\
\hline 6 & A strongly to very strongly more important than B \\
\hline 7 & A very strongly more important than B \\
\hline 8 & A very strongly to extremely stronger more important than B \\
\hline 9 & A extremely more important than B \\
\hline
\end{tabular}

In the assessment of vulnerability to people, Servi (2004) considered the variables: distance to a hospital for medical help; type of access road for access to emergency personnel; and building vulnerability. A modified version of the pairwise comparison applied by Servi (2004) was used for the building and people vulnerability analyses in this study by removing the two variables not used and adjusting the weight to sum to 1 . Figures 4 and 5 summarise the proposed approach using the weights from the pairwise comparison as provided in Tables 2 and 3. 
Table 2. Vulnerability analysis for buildings by pairwise comparison of the identified attributes: number of floors and construction material [adapted from Servi (2004)].

\begin{tabular}{|c|c|c|c|}
\hline Criterion & $\begin{array}{c}\text { Number of } \\
\text { floors }\end{array}$ & $\begin{array}{c}\text { Construction } \\
\text { material }\end{array}$ & $\begin{array}{c}\text { Rounded } \\
\text { Normalized } \\
\text { sums (weights) }\end{array}$ \\
\hline Number of floors & 1 & 0.33 & 0.1 \\
\hline Construction material & 3 & 1 & 0.9 \\
\hline & & Sum: & 1 \\
\hline
\end{tabular}

Table 3. Vulnerability analysis for people by pairwise comparison of the identified attributes: building vulnerability, type of road and distance to hospital [adapted from Servi (2004)].

\begin{tabular}{|c|c|c|c|c|}
\hline Criterion & $\begin{array}{c}\text { Building } \\
\text { vulnerability }\end{array}$ & $\begin{array}{c}\text { Type of } \\
\text { road }\end{array}$ & $\begin{array}{c}\text { Distance to } \\
\text { hospital }\end{array}$ & $\begin{array}{c}\text { Rounded } \\
\text { Normalized } \\
\text { sums } \\
\text { (weights) }\end{array}$ \\
\hline Building vulnerability & 1 & 3 & 4 & 0.61 \\
\hline Type of road & 0.33 & 1 & 5 & 0.30 \\
\hline Distance to hospital & 0.25 & 0.2 & 1 & 0.09 \\
\hline & & & Sum: & 1 \\
\hline
\end{tabular}

The attribute values for the buildings for this study were taken from the building catalogue and rated. In the case of infrastructure, the number of floors served as a rating tool (i.e. a building with 12 floors had a rating of 12) but construction materials were rated on a linear scale as done in Servi (2004). The factors for the human vulnerability analysis were assigned to the calculated value (i.e. the actual distance to the nearest medical facility able to provide casualty support along the road network). The factor representing the type of road was rated as shown in Servi (2004). Each of the ratings was then normalised. The normalization process involves transforming the values to range between 0 and 1 . This is used for comparing variables on differing scales and is performed by dividing the value (number of floors of a building) by the sum of all the values within that field.

\subsection{Seismic Loss Assessment}

The last part of the risk assessment estimates potential loss. Building valuation as provided by CoJ was used to derive the direct monetary economic loss of the building. Similarly, the number of people in each building should be used to derive the potential casualties but unfortunately, this data is not readily available for CoJ. As an alternative, the day-time population statistics per enumeration area from GeoTerralmage were used instead. The initial building catalogue contained 52 buildings, but only 33 of them were used in the vulnerability assessment of people since population statistics were not available for the others.

\subsection{Seismic Risk Assessment}

A weighted linear combination (WLC) is used to calculated the seismic risk for buildings or a group of people as per equation (3),

$$
S R_{i}=H_{i} \times V_{i} \times P L_{i} \times 10000
$$

where the seismic risk of a building or of a group of people at a specific location $\left(S R_{i}\right)$; is equal to the multiplication of the seismic hazard in terms of intensity $\left(H_{i}\right)$ with the vulnerability $\left(V_{i}\right)$ and the normalized potential loss (valuation) $\left(P L_{i}\right)$. The result is multiplied by a constant $(10,000)$ to work with values greater than 1. 


\section{RESULTS AND DISCUSSION}

The results of the seismic vulnerability and potential loss assessments are independent of the size of a seismic event. Figures 9 to 12 are consequently the same for the hypothetical earthquake magnitudes of magnitude $M_{L} 5.3$ and $M_{L}$ 6.0. The driving force behind risk assessment is the underlying hazard.

The analysis shows that building vulnerability is higher in the Johannesburg CBD than in the Sandton CBD (Fig. 9). The south-west concentration of buildings in the Johannesburg CBD exhibits a higher level of vulnerability than the rest of the area. This is attributed to the nearest medical facility being far away and the building vulnerabilities being high. The potential monetary loss, on the other hand, is predicted to be significantly higher in Sandton than in Johannesburg (Fig. 10). The reason for this is that most high-rise buildings in the Sandton CBD were constructed from 2004 onwards, while the high-rise buildings in the Johannesburg CBD were constructed before 1980, making building prices in the Sandton CBD much higher.

The seismic vulnerability with regards to human life seems to be higher in the Sandton CBD than in the Johannesburg CBD (Fig. 11), mainly due to the poor spatial distribution of medical facilities and the lack of main roads in the Sandton CBD. The vulnerability of people could possibly be reduced by improving access routes and developing more medical facilities in the respective CBDs. The assessment of potential loss to the population (Fig. 12) did not show a clear pattern, except for the Johannesburg CBD having a higher population density than the Sandton CBD. This is attributed to high concentration of offices in the Johannesburg CBD. The results in Figures 11 and 12 are based on the assumption that the building population follows the daytime population density of the surrounding enumeration area.

Figures 13 and 15 (buildings) and Figs. 14 and 16 (people) show the final seismic risk maps that were produced using the risk equation (3) for the $M_{L} 5.3$ and $M_{L} 6.0$ scenario events, respectively.

Higher building valuations in Sandton increase the overall seismic risk to the buildings in this area (Fig. 13). The seismic risk is much higher for taller buildings in the Johannesburg CBD compared to buildings under 25 stories high. The final seismic risk assessment for the population is much higher in the Johannesburg CBD than the Sandton CBD (Fig. 14), as the seismic hazard and potential loss of people was higher in the Johannesburg CBD.

The added advantages of using GIS in seismic risk assessment can be seen in these results: heterogeneous information in a variety of formats and from various application domains was integrated into a single map. This information included aerial photography, locations of buildings and their valuations, the road network, locations of medical facilities, and estimates of building occupancy. The information was available in raster and vector format, the latter as a combination of points (locations), lines (roads) and polygons (population estimates). GIS was used as a tool to assess different hypothetical risk scenarios. Once the data had been prepared and set up in the GIS, adding additional hypothetical scenarios was simple. Such GIS-based risk assessments provide an intuitive, easy-to-interpret tool to make a complex phenomenon understandable; for example, the different coloured symbols in the maps simplify the interpretation of the seismic risk associated with individual buildings. In further work we plan to prepare additional visualizations of the risk maps (e.g. with different symbols and/or three-dimensional symbols) and conduct user studies to assess which kind of visualization is most suitable for non-specialist users in disaster management centres.

Another advantage is that the spatial distribution of the seismic risk in relation to infrastructures, such as towns, medical facilities and the road network, is highlighted in the maps. This information makes it possible to improve planning for disasters; for example, if one knows where the most vulnerable buildings are, additional medical facilities or improved access to medical facilities can be planned. The maps also show areas that are very unlikely to be affected, and therefore do not have to be included in disaster management. The maps in 
this paper showed the results of two specific suburbs, but data is available for the remainder of CoJ and could be interactively explored at different scales or zoom levels.
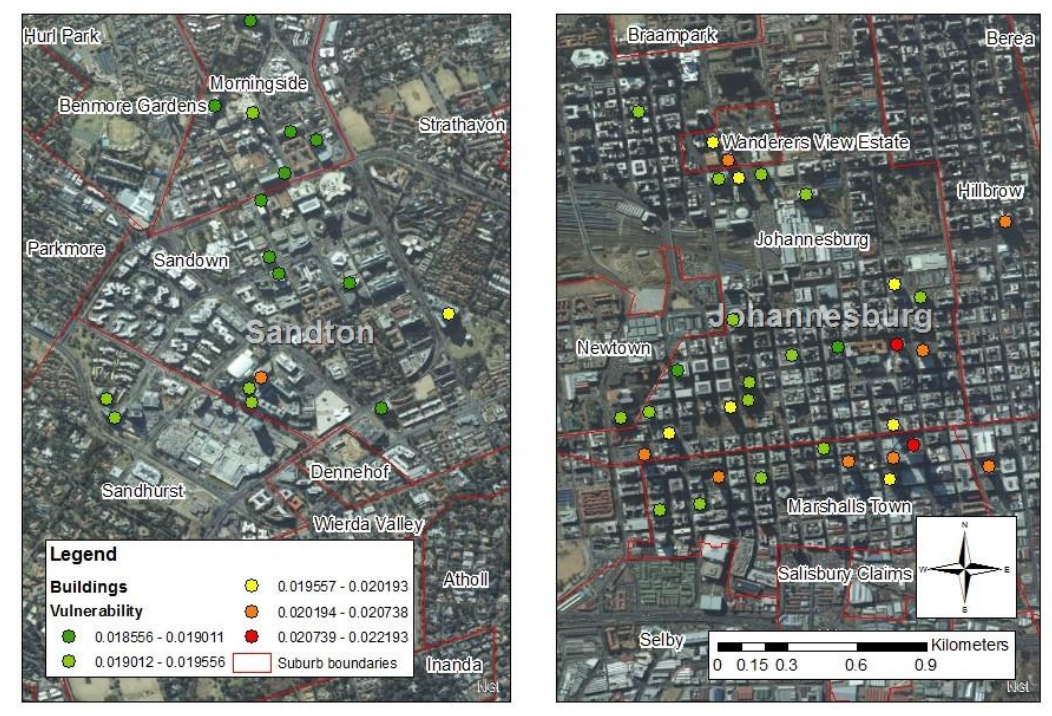

Fig 9. Building vulnerability in the Sandton and Johannesburg CBD's.
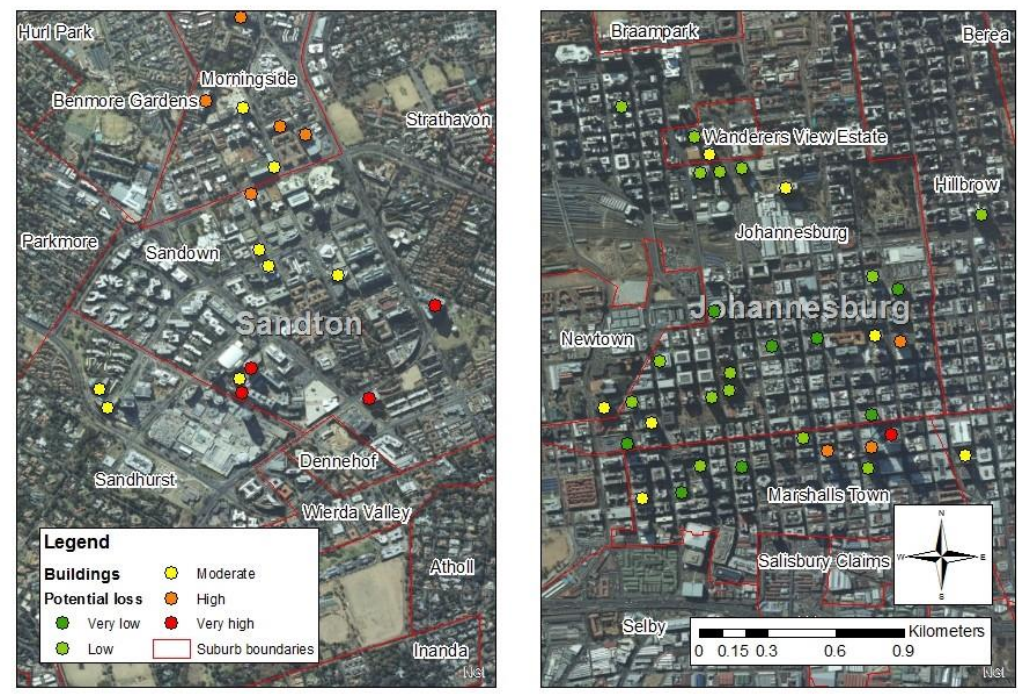

Fig 10. Potential monetary loss of each building in the Sandton and Johannesburg CBD's. 

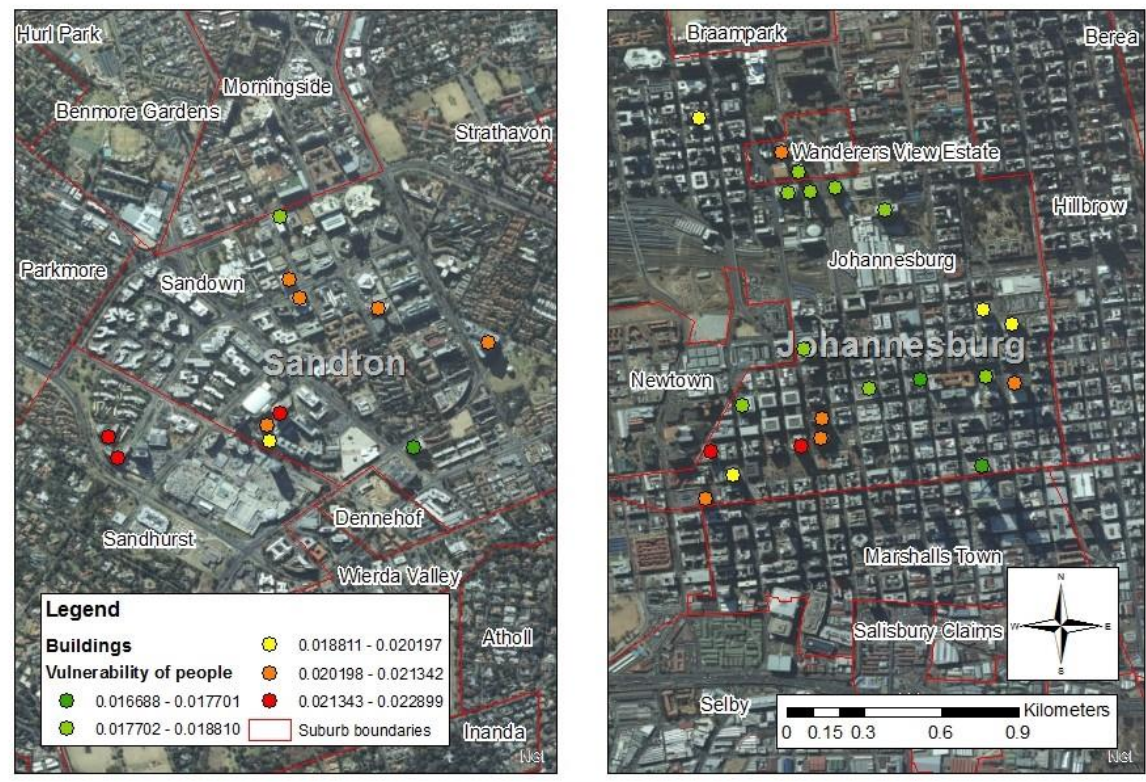

Fig 11. The vulnerability of people in the Sandton and Johannesburg CBD's.
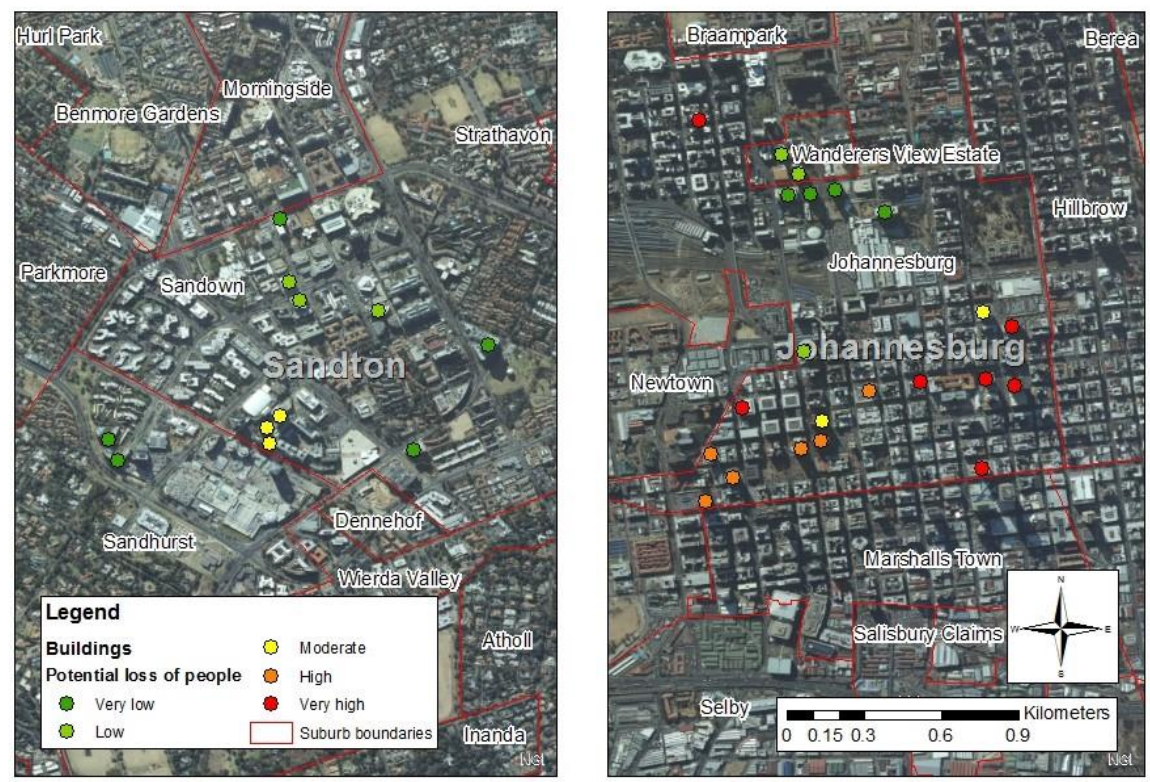

Fig 12. The potential loss of human lives in the Sandton and Johannesburg CBD's. 

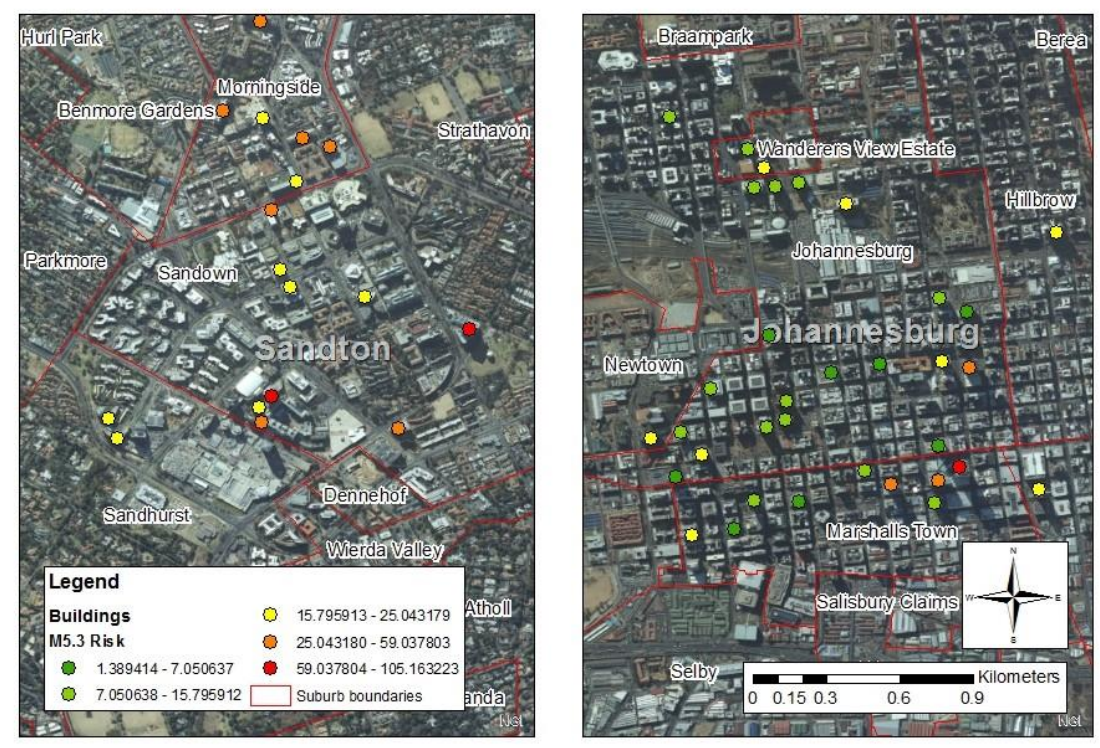

Fig 13. Seismic risk of buildings in the Sandton and Johannesburg CBD's based on a seismic event of magnitude $M_{L} 5.3$.
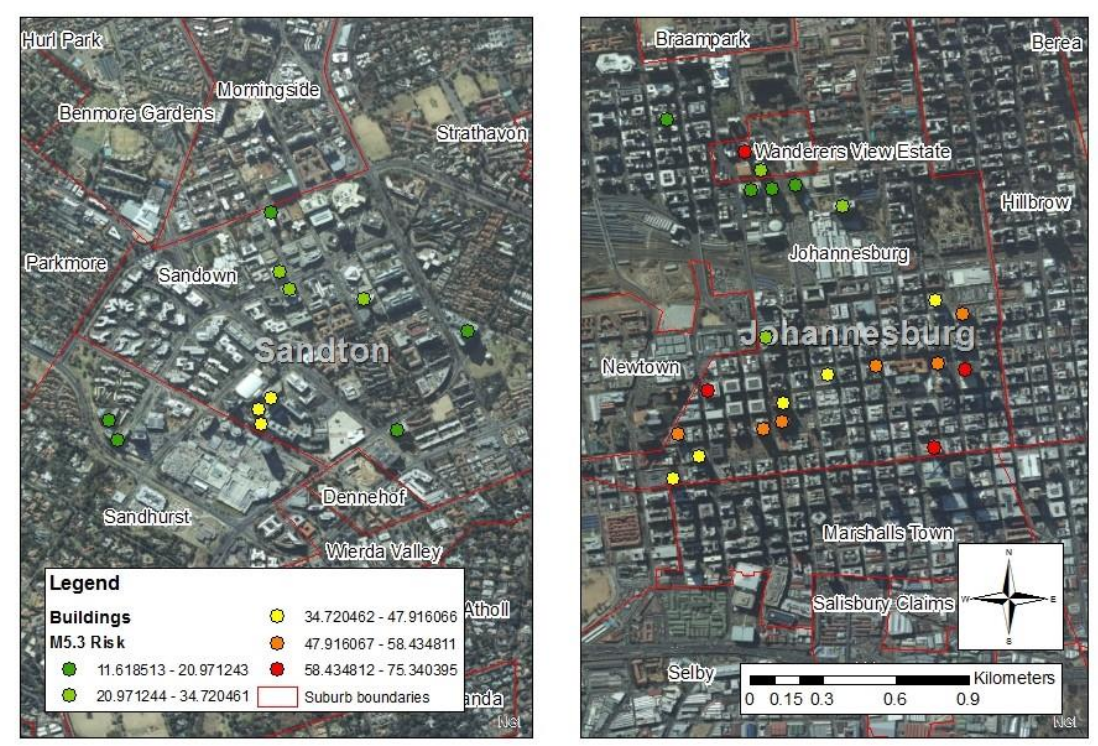

Fig 14. Seismic risk of people in the Sandton and Johannesburg CBD's based on a seismic event of magnitude $M_{L}$ 5.3. 

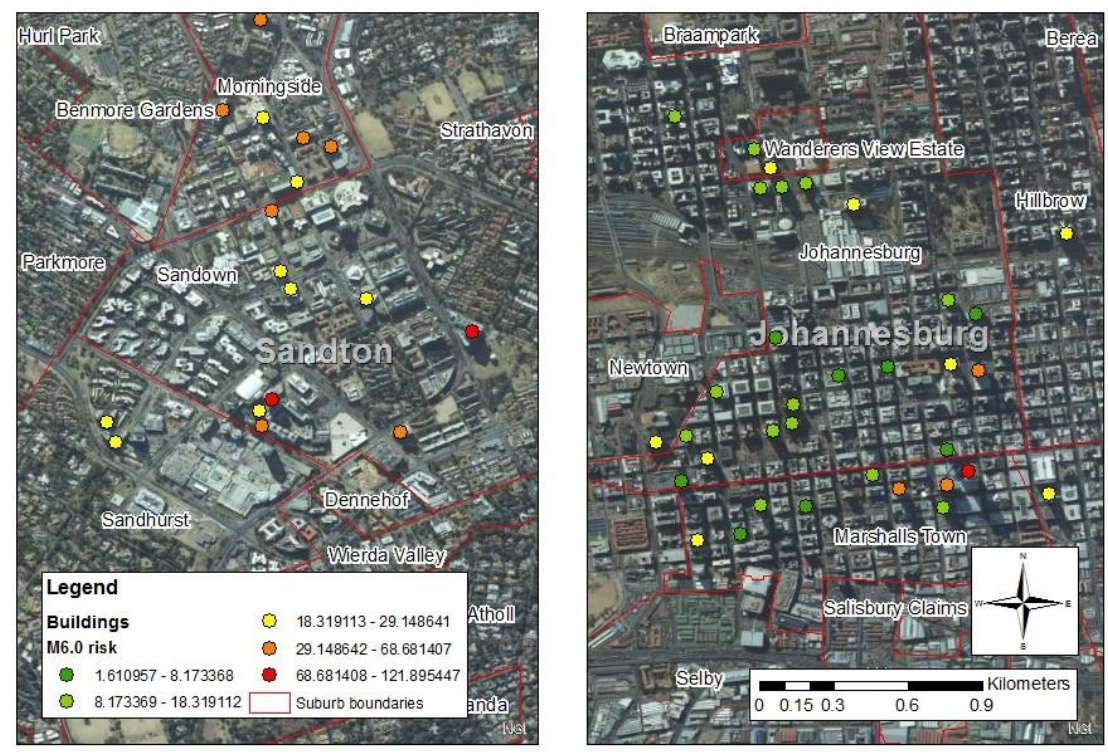

Fig 15. Seismic risk of buildings in the Sandton and Johannesburg CBD's based on a seismic event of magnitude $M_{L} 6.0$.
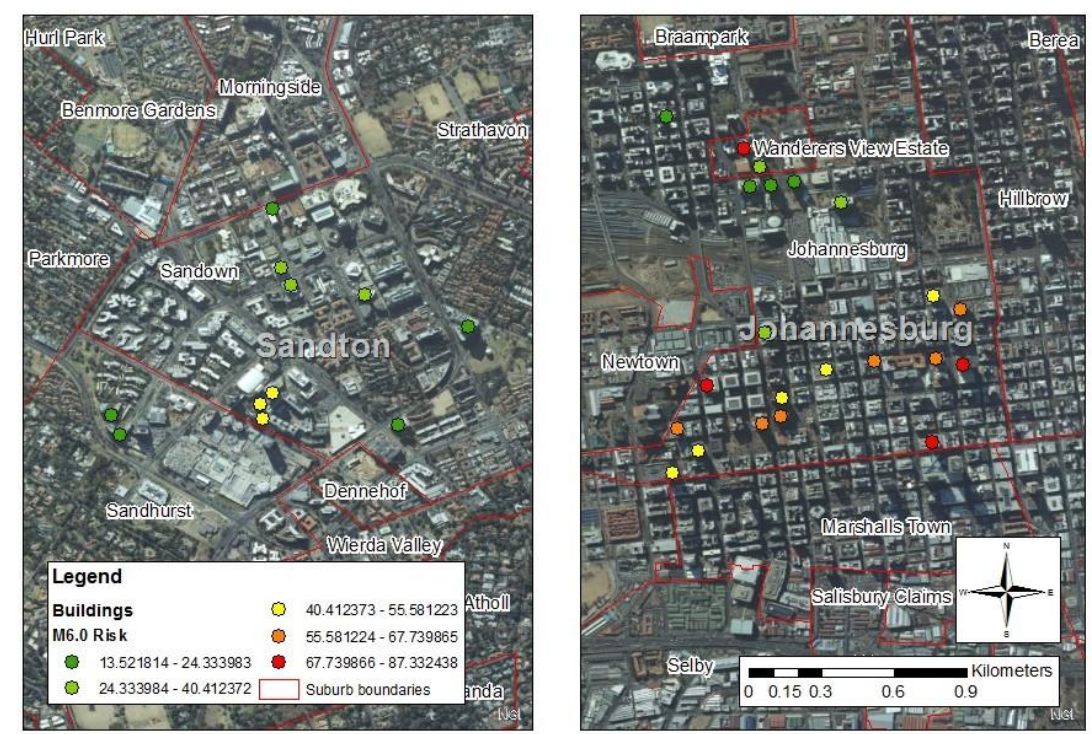

Fig 16. Seismic risk of people in the Sandton and Johannesburg CBD's based on a seismic event of magnitude $M_{L} 6.0$.

\section{CONCLUSION}

In this paper, we described a GIS approach to deterministic seismic risk assessment. The risk of two scenario earthquakes was assessed for the population and buildings in two suburbs of CoJ. The scenario earthquakes were based on hypothetical events in the Germiston area, which is currently experiencing high levels of seismic activity. The two suburbs have mainly high-rise buildings filled with hundreds of people during the day. They are also situated in the economic hub of South Africa. Building vulnerability, the road infrastructure, distance to medical facilities and building occupancy were considered for the seismic risk to people, while the number of floors and construction material of a building, as well as its value on the municipal valuation roll, were considered for seismic risk to buildings. 
The resulting maps show that despite the fact that seismic vulnerability to buildings is higher in Johannesburg, the potential monetary loss is higher in Sandton. This can be attributed to the fairly recent extensive expansion in construction in the Sandton CBD. Poor spatial distribution of medical facilities and the lack of main roads in Sandton and the south-west of the Johannesburg CBD are factors increasing the seismic vulnerability of people. This GIS-based deterministic risk assessment revealed vulnerabilities and potential losses that would have been difficult to identify and assess otherwise. The results illustrate the benefits of using GIS-based seismic risk assessments for a better understanding of risk, which can lead to improved disaster preparedness.

In further work we plan to prepare additional visualizations of the risk maps (e.g. with different symbols and/or three-dimensional symbols) and conduct user studies to assess which kind of visualization is most suitable for users in disaster management centres.

Acknowledgments. We express our gratitude to the following institutions, companies and people who assisted in this project: the Council for Geoscience, Michelle Grobbelaar; Prof. Chris Roth from the University of Pretoria; GeoTerralmage; SkyscraperPage.com; City of Johannesburg Corporate GIS, Deena Naidoo, Marcelle Hattingh; Eskom, Adri de le Rey, S'lindi Mhlongo.

\section{References}

Algermissen, ST., Reinehart W, Dewey J, Steinbrugge KW, Lagorio HJ, Degenkolb HJ, Cluff LS, McClure FE, Scott S, Gordon RF (1972) A study of earthquake losses in the San Francisco Bay Area: Data and Analysis. Washington, D.C. National Oceanic and Atmospheric Administration (NOAA).

Applied Technology Council (1985) ATC-13 Earthquake Damage Evaluation Data for California, Redwood City, CA.

ASCE/SEl Seismic Rehabilitation Standards Committee. (2007) Seismic Rehabilitation of Existing Buildings (ASCE/SEl 41-06). American Society of Civil Engineers, Reston, VA.

Birch DJ (2013) Identifying Instability in the Rock Mass Caused by Water Ingress into Abandoned Mines. MSC Physics Dissertation, University of Pretoria, South Africa.

Carder DS (1945) Seismic investigations in the Boulder Dam area, 1940-1944, and the influence of reservoir loading on local earthquake activity. Bulletin of the Seismological Society of America, 35(4), 175-192.

Ciriannia F, Leonardia G, Scopelliti F (2008) A methodology for assessing the seismic vulnerability of highway systems, AIP Conference Proceedings, v1020 PART 1, Reggio Calabria, Italy.

Coetzee H, Hobbs PJ, Burgess JE, Thomas A, Keet M (2010) Mine water management in the Witwatersrand goldfields with special reference to acid mine drainage, Report to the inter-ministerial committee on acid mine drainage, Pretoria

Davies N, Kijko A (2003) Seismic risk assessment: with an application to the South African insurance industry, South African Actuarial Journal, 3(1), pp. 1-28.

Du Plessis I, Liebenberg K, Smit A, Coetzee S, Kijko A (2015) Preliminary investigation into the cause of acid mine water induced seismicity in Johannesburg. South African Journal of Geomatics, 4(3), 299-308.

Durrheim RJ (2006) The risks to miners, mines, and the public posed by large seismic events in the gold mining districts of South Africa. Third International Seminar on Deep and High Stress Mining, Quebec City, Canada, 2-4 October 2006, pp 1-14

Esterhuyse S, Avenant M, Watson M, Redelinghuys N, Kijko A, Glazewski J, Plit LA, Kemp M, Smit A, Sokolic F, Vos AT, Reynolds D, Von Maltitz M, Van Tol J, Bragg C, Van Soelen B, Ouzman S (2014) Development of an interactive vulnerability map and monitoring framework to assess the potential environmental impact of unconventional oil and gas extraction by means of hydraulic fracturing. WRC Report No. 2149/1/14. ISBN 9781431205899.

Fenton $\mathrm{CH}$, Adams J, Halchuk S (2006) Seismic hazards assessment for radioactive waste disposal sites in regions of low seismic activity. Geotechnical \& Geological Engineering, 24(3), pp579-592. 
FEMA 249 (1994) Assessment of the State-of-the-Art Earthquake Loss Estimation Methodologies (1994). Federal Emergency Management Agency, FEMA-249/June 1994, Earthquake Hazard Reduction Series 70, pp. 300.

Frolova N, Larinov V, Bonnin J (2006) Expected damage and loss assessment in "Emergency" mode at global scale: Analysis of uncertainties. First European Conference on Earthquake Engineering and Seismology, Geneva, Switzerland, 3-8 September 2006. Paper Number: 1264.

Goldbach O (2010) What is the Seismic Risk of Mine Flooding?, Science Real and Relevant Conference 2010, CSIR, Pretoria, South Africa.

Grünthal G (1998) European Macroseismic Scale (EMS-98), CONSEIL DE L'EUROPE, Centre Européen de Géodynamique et de Séismologie, Vol 15, Luxemburg.

Keilis-Borok VI, Kronrod TL, Molchan GM (1984) Seismic risk for the largest cities of the world; intensity VIII or more. Geneva Papers on Risk and Insurance, pp 255-270.

Kijko A (2011) Seismic hazard. In: H. Gupta (ed.), Encyclopedia of Solid Earth Geophysics (pp. 1107-1121). Springer Netherlands.

Kijko A, Retief SJP, Graham GI (2002) Seismic hazard and risk assessment for Tulbagh, South Africa: Part Iassessment of seismic hazard. Natural Hazards, 26(2), pp175-201.

Kijko A, Smit A, Kahle B, Glazewski J (2016) Hydraulic Fracturing, Waste Water Pumping and Seismicity. Chapter 10 In: J. Glazewski (ed), Proposed Hydraulic Fracturing in the Karoo: Critical Perspectives, Juta and Co, Cape Town

Kijko A, Smit A, Van de Coolwijk N, Kilian Z (2012) 'Methodology for probable maximum loss calculation and potential implications of acid mine water for the South African general insurance industry' Presentation at Actuarial Society 2012 Convention, 16-17 October 2012, Cape Town, South Africa.

Kijko, A, Smit A, Van De Coolwijk N (2015) A scenario approach to estimate the maximum foreseeable loss for buildings due to an earthquake in Cape Town. South African Actuarial Journal, 15, pp.1-30.

Lay T, Wallace TC (1995) Modern Global Seismology, International Geophysics, Volume 58, First Edition, Academic Press, San Diego.

Malczewski J (1999) GIS and Multicriteria Decision Analysis, First Edition, John Wiley \& Sons, New York.

Mualchin L (2011) History of Modern Earthquake Hazard Mapping and Assessment in California Using a Deterministic or Scenario Approach, Pure and Applied Geophysics, 168(3-4), pp. 383-407.

Reitherman R (1985) A Review of Earthquake Damage Estimation Methodologies, Earthquake Spectra, EERI, 1, 805-847.

Richter CF (1958) Elementary Seismology. Freeman WH, San Francisco

Rivas-Medina A, Gaspar-Escribano JM, Benito B, Bernabé MA (2013) The role of GIS in urban seismic risk studies: application to the city of Almería (southern Spain). Natural Hazards and Earth System Sciences,13(11), 2717-2725.

Servi M (2004) Assessment of vulnerability to Earthquake Hazards using Spatial Multicriteria Analysis: Odunpazari, Eskisehir Case Study, MSc dissertation in Geodetic and Geographic Information Technologies, Middle East Technical University, Ankara, Turkey.

Sieberg, A. (1923). "Erdbebenkunde", Jena, Ficher, August), modified and condensed; Quoted from Wood, H.O., and Neumann, F., (1931). "Modified Mercalli Intensity Scale of 1931", Bulletin of the Seismological Society of America, Vol. 21, No. 4, pp. 277-283.

SkyScraperPage.com (2014a) Johannesburg Skyscraper Map, viewed 16 September 2014 <http://skyscraperpage.com/cities/maps/?citylD=755>.

SkyscraperPage.com (2014b) Sandton Skyscraper Map, viewed 16 September 2014 <http://skyscraperpage.com/cities/maps/?citylD=1349>.

Statistics South Africa (2013) Census 2011 sub-place areas [dataset], Pretoria, Statistics South Africa, Accessed 26 June 2013.

Steinbrugge KV (1982) Earthquakes, Volcanoes, and Tsunamis: An Anatomy of Hazards, Skandia America Group, New York. 
[Acta Geophysica, Vol 65, Issue 4, pp645-657]

Van Aswegen G (2005) Routine seismic hazard assessment in some South African mines. In: Y. Potvin and M. Hudyma (eds.), Proceedings of the Sixth International Symposium on Rockburst and Seismicity in Mines. Nedlands: Australian Centre for Geomechanics (pp. 435-444).

Van Westen CJ (2013) Remote Sensing and GIS for Natural Hazards Assessment and Disaster Risk Management. In: J.F. Schroder and M.P Bishop (eds), Treatise on Geomorphology Academic Press, Elsevier, San Diego, pp. 259-298.

Whitman RV (1986) Earthquake Loss Estimation Methodology. In: A. Vogel and K. Brandes (eds.), Earthquake Prognostics, Hazard Assessment, Risk Evaluation and Damage Prevention, Proceedings from the 2nd International Seminar held in Berlin, June 24-27, 1986. Friedr. Vieweg \& Son, Braunschweig/ Wiesbaden, 1986, 259-278.

Wood HO, F Neumann F (1931) Modified Mercalli intensity scale of 1931. Seismological Society of America.

Yuan Z (2003) Development of a GIS Interface for Seismic Hazard Assessment, MSc dissertation in Earth Resources and Environmental Geoscienes, International Institute for Geo-Information Science and Earth Observation, Enschede, the Netherlands. 